Ethos (Jurnal Penelitian dan Pengabdian Masyarakat): 149-160

\title{
Upaya Mempertahankan Kabupaten Karawang Sebagai lumbung Padi NASIONAL
}

\author{
${ }^{1}$ Ivan Chofyan, ${ }^{2}$ Uton Rustan, dan ${ }^{3}$ Asep Hariyanto \\ ${ }^{1,2,3}$ Fakultas Teknik, Program Studi Perencanaan Wilayah dan Kota Universitas Islam Bandung, \\ Jl. Tamansari No. 1 Bandung 40116 \\ e-mail: ${ }^{1}$ vanchofyan@yahoo.co.id, ${ }^{2}$ rustanuton2@gmail.com, ${ }^{3}$ asep_har@yahoo.co.id
}

\begin{abstract}
Abstrak. Kabupaten Karawang dikenal sebagai lumbung padi nasional dan tercatat sebagai daerah produsen beras terbesar kedua setelah Kabupaten Indramayu. Sebagai lumbung padi nasional, Kabupaten Karawang ditugaskan untuk surplus gabah sebanyak 1,5 juta ton. Di sisi lain, meningkatnya jumlah penduduk dan perkembangan Kabupaten Karawang sebagai salah satu kawasan strategis ekonomi mengakibatkan permintaan lahan meningkat dan berpengaruh terhadap sawah yang ada. Tujuan studi ini adalah untuk menemukenali keberadaan Kabupaten Kara wang sebagai sebagai lumbung padi nasional, menetapkan luas lahan sawah yang harus diproteksi sebagai upaya mempertahankan produksi padi, dan mengidentifikasi ketersediaan air yang dapat dipergunakan sebagai air irigasi, sebagai faktor pendukung dalam meningkatkan produksi padi. Analisis yang digunakan dalam studi ini adalah proyeksi penduduk, analisis surplus defisit, analisis kebutuhan lahan sawah dan anilisis kebutuhan air irigasi. Kesimpulan dari penelitian ini adalah: 1) Kabupaten Karawang tidak dapat memenuhi target surplus gabah sebesar 1,5 juta ton apabila penyelenggaraan kegiatan pertanian dilakukan seperti sekarang;2) Apabila luas sawah tidak berkurang, peningkatan produktivitas tanah dan intensitas pertanaman secara bersamaan dapat menghasilkan surplus gabah sebesar 1,5 juta ton. Walaupun demikian, target surplus 1,5 juta ton ini hanya berlangsung sampai dengan Tahun 2017; dan 3) Debit air sungai yang melalui Kabupaten Karawang lebih besar jika dibandingkan dengan kebutuhan air irigasi, sehing ga dimungkinkan adanya penambahan lahan sawah. Beberapa rekomendasi yang dapat diajukan sehubungan dengan kesimpulan di atas adalah sebagai berikut: 1) Lahan sawah yang ada di Kabupaten Karawang perlu diproteksi, sehing ga pengembangan kawasan permukiman dan industri harus dijauhkan dari lahan sawah; 2) Peningkatan produktivitas tanah dan intensitas pertanaman harus didukung oleh jaringan irigasi yang memadai, sehingga jaringan irigasi yang ada harus dipelihara dan ditingkatkan penggunaannya; dan 3) Dalam jangka panjang, percetakan sawah baru di Kabupaten Karawang harus dilakukan agartarget surplu gabah 1,5 juta ton dapat dicapai.
\end{abstract}

Kata kunci: Lumbung Padi, Sawah, Irigasi.

\section{Pendahuluan}

Pembangunan pertanian telah memberikan sumbangan besar dalam pembangunan nasional, baik sumbangan langsung seperti dalam pembentukan PDB, penyerapan tenaga kerja, peningkatan pendapatan masyarakat, perolehan devisa melalui ekspor dan penekanan inflasi, maupun sumbangan tidak langsung melalui penciptaan kondisi yang kondusif bagi pelaksanaan pembangunan dan hubungan sinergis dengan sektor lain. Menurut Arifin (2001), pada situasi krisis ekonomi yang dipicu oleh krisis moneter yang terjadi pada akhir tahun 90-an, sektor pertanian kembali berperan sebagai sektor penyelamat pembangunan nasional, melalui: (a) Perannya dalam menyediakan kebutuhan pangan pokok dalam jumlah yang memadai; (b) Perannya dalam perolehan 
devisa melalui ekspor; (c) Perannya sebagai reservoar (penampung) tenaga kerja yang kembali ke perdesaan sebagai akibat dampak krisis; (d) Perannya dalam menanggulangi kemiskinan masyarakat yang semakin meningkat; (e) Perannya dalam pengendalian inflasi; dan (f) Dengan tingkat pertumbuhan yang masih positif, sektor pertanian berperan dalam menjaga laju pertumbuhan nasional. Menurut Irawan (2005), posisi pertanian akan sangat strategis apabila terjadi perubahan pola pikir masyarakat yang cenderung memandang pertanian hanya sebagai penghasil (output) komoditas an sich menjadi pola pikir yang melihat multi fungsi dari pertanian.

Kabupaten Karawang dikenal sebagai lumbung padi nasional dan tercatat sebagai daerah produsen beras terbesar kedua setelah Kabupaten Indramayu. Saat ini lahan sawah di Kabupaten Karawang mulai terancam seiring dengan berkembangnya sektor industri di daerah tersebut serta ancaman dari daerah sekitarnya. Kawasan Bodetabek (Bogor, Depok, Tangerang dan Bekasi) sebagai penyangga Ibukota sudah tidak bisa menampung lagi dan berdampak kepada wilayah sekitarnya, khususnya Kabupaten Karawang yang berdekatan dengan kawasan tersebut. Kemudahan akses yang dilalui oleh jalur pantura serta letak geografis yang berada di dua kota besar yaitu Jakarta dan Bandung mengakibatkan daerah ini menjadi daerah penyangga yang strategis untuk menjadi salah satu pusat perekonomian sehingga sektor-sektor ekonomi pun menjadi tumbuh.

Meningkatnya jumlah penduduk serta perkembangan Kabupaten Karawang menjadi salah satu kawasan strategis ekonomi mengakibatkan permintaan lahan meningkat dan berpengaruh terhadap lahan-lahan sawah di Kabupaten Karawang. Selama dua tahun antara tahun 2011 - 2013 terjadi pengurangan luas lahan sawah 511 Ha, dengan dengan demikian rata-rata pengurangan lahan sawah pertahun 255,5 hektar per tahun (Tabel 1).

Tabel 1: Luas Lahan Sawah di Kabupaten Karawang

\begin{tabular}{|c|c|c|}
\hline Tahun & $\begin{array}{l}\text { Lahan Sawah } \\
\text { (Ha) }\end{array}$ & $\begin{array}{l}\text { Pengurangan Luas Lahan Sawah } \\
\text { (Ha) }\end{array}$ \\
\hline 1994 & 94.259 & \multirow{2}{*}{803} \\
\hline 2005 & 93.456 & \\
\hline 2006 & 94.385 & \multirow{2}{*}{74} \\
\hline 2007 & 94.311 & \\
\hline 2011 & 94.311 & \multirow{2}{*}{511} \\
\hline 2013 & 93.800 & \\
\hline
\end{tabular}

Sebagai daerah pertanian Kabupaten Karawang dilewati oleh Sungai Citarum, yang sangat penting keberadaannya karena menjadi sumber air irigasi sebagai salah satu sarana produksi padi. Menurut data Dinas Pengelolaan Sumber Daya Air Provinsi Jawa Barat, Kabupaten Karawang memiliki 7 DAS, yaitu: 1. Sub DAS Citarum Hilir, 2. DAS Cisoga, 3. DAS Ciwadas, 4. DAS Ciderewak, 5.DAS Cibulan, 6. DAS Cilamaya, dan 7. DAS Cibeet. Walaupun saat ini Kabupaten Karawang menjadi kawasan strategis perekonomian nasional, tetapi karena keberadaan lahan dan air sangat mendukung kegiatan pertanian, maka keberadaan Kabupaten Karawang sebagai lumbung padi perlu dipertahankan.

Penelitian ini bertujuan untuk 1) Menemukenali keberadaan Kabupaten Karawang sebagai sebagai lumbung padi nasional; 2)Menetapkan luas lahan sawah 
yang harus diproteksi sebagai upaya mempertahankan produksi padi; dan 3) Mengidentifikasi ketersediaan air yang dapat dipergunakan sebagai air irigasi, sebagai faktor pendukung dalam meningkatkan produksi padi.

\section{Konsep Swasembada Pangan, Kemandirian Pangan, Kedaulatan Pangan, dan Ketahanan Pangan}

Menurut Arifin (2004), swasembada pangan umumnya merupakan capaian peningkatan ketersediaan pangan dengan ruang lingkup wilayah nasional. Kemandirian pangan merupakan kondisi dinamis karena sifatnya lebih menekankan pada aspek perdagangan atau komersialisasi. Kedaulatan pangan adalah kebebasan dan kekuasaan rakyat serta komunitasnya untuk menuntut dan mewujudkan hak untuk mendapatkan produksi pangan sendiri dan tindakan melawan kekuasaan perusahaan-perusahaan serta kekuatan lainnya yang merusak sistem produksi pangan rakyat melalui perdagangan, investasi, serta alat kebijakan lainnya.

Ketahanan pangan menurut definisi FAO (1997) merupakan situasi dimana semua rumah tangga mempunyai akses baik fisik maupun ekonomi untuk memperoleh pangan bagi seluruh anggota keluarganya, dimana rumah tangga tidak beresiko mengalami kehilangan kedua akses tersebut. Seperti yang banyak diketahui, baik secara nasional maupun globlal, ketersediaan pangan yang melimpah melebihi kebutuhan pangan penduduk tidak menjamin bahwa seluruh penduduk terbebas dari kelaparan dan gizi kurang.

Laju pertumbuhan penduduk di Indonesia termasuk pesat. Berdasarkan data BPS, pada tahun 1900 jumlah penduduk sekitar 40 juta, tahun 1970 menjadi 120 juta jiwa, tahun 1980 menjadi 147 juta jiwa, tahun 1990 menjadi 179 juta jiwa, tahun 2000 menjadi 206 juta, dan sensus penduduk terakhir tahun 2010 mencapai 237 juta jiwa. Selama kurun waktu 40 tahun telah terjadi peningkatan jumlah penduduk sebesar 117 juta jiwa. Pertambahan penduduk ini menyebabkan meningkatnya kebutuhan akan beras. Kebutuhan beras ini juga dipengaruhi oleh pola konsumsi makanan penduduk. Pola konsumsi makanan penduduk merupakan salah satu indikator sosial ekonomi masyarakat yang sangat dipengaruhi oleh budaya dan lingkungan setempat. Konsumsi beras per kapita per tahun Indonesia meningkat nyata yaitu $109 \mathrm{~kg}$ (1970), $122 \mathrm{~kg}$ (1980), $149 \mathrm{~kg}$ (1990), $114 \mathrm{~kg}$ (2000), dan $135 \mathrm{~kg}$ (2007) bahkan berdasarkan pada konsumsi energi yang sesuai dengan Pola Pangan Harapan (PPH) Nasional, konsumsi beras mencapai $140 \mathrm{~kg} / \mathrm{kapita} / \mathrm{tahun}$ atau mendekati konsumsi beras nasional 139,15 $\mathrm{kg} / \mathrm{kapita} / \mathrm{tahun}$ adalah sangat besar jika dibandingkan dengan negara lainnya di Asia. Konsumsi beras di Jepang hanya $60 \mathrm{~kg} / \mathrm{kapita} / \mathrm{tahun}$, sedangkan di Malaysia konsumsi beras hanya $80 \mathrm{~kg} / \mathrm{kapita} / \mathrm{tahun}$ (Arifin, 2004).

\section{Konsep tentang Lahan}

Secara akademis istilah "lahan" baru diperkenalkan pada dekade tahun 1970-an, yang dimaksudkan sebagai arti kata "land" dalam Bahasa Inggris. Pada awalnya untuk istilah lahan biasa dipergunakan kata "tanah". BPN misalnya, selalu menggunakan kata "tanah" karena mengacu pada UUPA yang dibuat pada tahun 1960, dimana istilah lahan belum diperkenalkan. Lahan diartikan sebagai lingkungan fisik dan biotik yang berkaitan dengan daya dukungnya terhadap perikehidupan dan kesejahteraan hidup 
manusia. Lingkungan fisik meliputi relief (topografi), iklim, tanah, dan air. Sedangkan lingkungan biotik meliputi hewan, tumbuhan, dan manusia (Arsyad dan Rustiadi, 2012). Sitorus (1995) mendefinisikan sumberdaya lahan (landresources) sebagai lingkungan fisik yang terdiri atas iklim, relief, tanah, air dan vegetasi serta benda yang ada di atasnya sepanjang ada pengaruhnya terhadap penggunaan lahan.

Suparmoko (2012), menyatakan bahwa penggunaan lahan pada umumnya tergantung pada kemampuan lahan dan lokasi lahan. Keputusan manusia untuk memperlakukan lahan ke suatu penggunaan tertentu selain disebabkan oleh faktor permintaan dan ketersediaan lahan demi meningkatkan kebutuhan dan kepuasan hidup, juga dipengaruhi oleh beberapa faktor diantaranya karakteristik fisik lahan (suitability), perilaku manusia, teknologi maupun modal, faktor ekonomi (feasibility) yang dipengaruhi oleh lokasi, aksesibilitas, sarana dan prasarana, faktor budaya masyarakat (culture) dan faktor kebijakan pemerintah (policy) (Rustiadi dkk, 2001).

Dalam kegiatan pertanian, lahan merupakan faktor produksi yang punya kedudukan penting. Sebagai faktor produksi, lahan mendapat bagian dari hasil produksi karena jasanya dalam produksi itu. Pembayaran atas jasa produksi ini disebut sewa (rent). Menurut Barlowe (1978), sewa lahan dapat dibedakan menjadi dua yaitu:

a. Sewa lahan (contract rent) sebagai pembayaran dari penyewa kepada pemilik di mana pemilik melakukan kontrak sewa menyewa dalam jangka tertentu.

b. Keuntungan usaha (economic rent atau land rent) yang merupakan surplus pendapatan di atas biaya produksi atau sebagai harga input lahan yang memungkinkan faktor produksi lahan yang dimanfaatkan dalam proses produksi.

Land rent dan contract rent merupakan dua konsep sewa yang penting yang digunakan dalam ekonomi sumber daya lahan. Selanjutnya Barlowe (1978) menyatakan bahwa lahan dengan sewa tertinggi cenderung dikuasai oleh kegiatan jasa, selanjutnya pada tingkat yang lebih rendah berturut-turut merupakan kegiatan industri, permukiman, pertanian, dan pada akhirnya dalam bentuk hutan hingga lahan tandus.

Alih fungsi lahan akan terus berlangsung sebagai dampak berbagai pembangunan yang memerlukan lahan seperti sektor industri, transportasi, pendidikan, dan permukiman. Winoto (2005) menyatakan bahwa ancaman alih fungsi lahan sawah ke depan sangat besar, yang mengancam sekitar 42,40\% luas sawah beririgasi di Indonesia, seperti tergambarkan dalam Rencana Tata Ruang Wilayah (RTRW) Pemerintah Kabupaten. Salah satu penyebabnya adalah adanya kepentingan Pemerintah Daerah untuk mengumpulkan dana melalui Pendapatan Asli Daerah (PAD), yang diupayakan antara lain dengan cara meningkatkan nilai ekonomi lahan pertanian. Perhitungan Pemda mungkin benar apabila nilai lahan pertanian hanya diukur dengan Pajak Bumi dan Bangunan (PBB) yang diperoleh, sehingga alih fungsi ke penggunaan untuk industri atau permukiman misalnya dianggap akan lebih menguntungkan. Namun, akan lain kesimpulannya bila nilai multifungsi pertanian dipertimbangkan juga dan dihitung nilai ekonomisnya.

\section{Pengertian dan Kebutuhan Air Irigasi}

Peraturan Pemerintah Nomor 20 Tahun 2006 tentang Irigasi, menyatakan bahwa irigasi adalah usaha penyediaan, pengaturan dan pembuangan air untuk menunjang pertanian yang jenisnya meliputi irigasi permukaan, irigasi rawa, irigasi air bawah tanah, irigasi pompa dan irigasi tambak. Irigasi berfungsi mendukung produktifitas usahatani guna meningkatkan produksi pertanian dalam rangka ketahanan pangan 
nasional dan kesejahteraan masyarakat khususnya petani yang diwujudkan melalui keberlanjutan sistem irigasi.

Menurut Partowijoto (2004) kebutuhan air atau water requirement dapat dirinci dan didefinisikan sebagai berikut:

a. Crop Water Requirement (CWR), yang meliputi evapotranspirasi atau consumptive use bagu suatu jenis tanaman.

b. Farm Water Requirement (FWR), yang merupakan kebutuhan air bagi suatu unit areal tanaman

c. Irrigation Water Requirement (IWR) yang mencakup jumlah kebutuhan air secara keseluruhan untuk suatu areal irigasi.

Kebutuhan air tanaman sangat dipengaruhi oleh keadaan iklim, jenis tanaman, cara bercocok tanam dan curah hujan. Untuk dapat menentukan jumlah kebutuhan air irigasi secara keseluruhan bagi suatu areal irigasi, perlu diketahui dengan tepat consumptive use / evapotranspirasi tanaman disamping efisiensi irigasi pada tingkat pemberian.

\section{Hasil dan Pembahasan}

\subsection{Analisis Kependudukan}

Berdasarkan data jumlah penduduk tahun 2003 - 2013, dapat diketahui laju pertumbuhan penduduk rata-rata selama 10 tahun tersebut yaitu sebesar 1,60\%. Dengan nilai $\mathrm{r}$ rata-rata sebesar $1,60 \%$, dan menggunakan rumus $\mathrm{Pt}=\mathrm{P} 0+(1+\mathrm{r}) \mathrm{t}$, maka dapat diketahui proyeksi penduduk sampai tahun 2033 seperti yang dapat dilihat pada tabel di bawah ini :

Tabel 2: Proyeksi Penduduk Kabupaten Karawang

\begin{tabular}{|c|c|c|c|}
\hline Tahun & $\begin{array}{c}\text { Jumlah Penduduk } \\
\text { (Jiwa) }\end{array}$ & Tahun & $\begin{array}{c}\text { Jumlah Penduduk } \\
\text { (Jiwa) }\end{array}$ \\
\hline 2014 & 2.259 .147 & 2024 & 2.564 .153 \\
\hline 2015 & 2.287 .939 & 2025 & 2.596 .832 \\
\hline 2016 & 2.317 .098 & 2026 & 2.629 .928 \\
\hline 2017 & 2.346 .628 & 2027 & 2.663 .445 \\
\hline 2018 & 2.376 .535 & 2028 & 2.697 .390 \\
\hline 2019 & 2.406 .823 & 2029 & 2.731 .767 \\
\hline 2020 & 2.437 .497 & 2030 & 2.766 .582 \\
\hline 2021 & 2.468 .562 & 2031 & 2.801 .841 \\
\hline 2022 & 2.500 .023 & 2032 & 2.837 .550 \\
\hline 2023 & 2.531 .885 & 2033 & 2.873 .713 \\
\hline
\end{tabular}

Sumber: Hasil Perhitungan

\subsection{Analisis Surplus Defisit}

Kabupaten Karawang sebagai lumbung padi mempunyai peran penting dalam menjaga swasembada beras nasional tentunya demi menjaga swasembada beras nasional karawang harus memenuhi target surplus gabah sebesar 1,5 juta ton/tahun untuk mendukung target 10 juta surplus beras nasional (Dinas Pertanian, Kehutanan, Perkebunan dan Peternakan Kabupaten Karawang, 2013). Perhitungan analisis surplus 
defisit gabah yang ada di Kabupaten Karawang untuk mengetahui surplus atau sisa beras. Nilai surplus sudah dikurangi dengan kebutuhan konsumsi beras penduduk Kabupaten Karawang dan surplus ini untuk pemenuhan beras tingkat nasional. Dengan menggunakan asumsi:

- Standar konsumsi $99 \mathrm{~kg} / \mathrm{kapita} / \mathrm{tahun}$

- Produksi dan produktivitas tetap berdasarkan data BPS tahun 2013.

- Intensitas pertanaman 2 kali dalam setahun (IP berdasarkan data).

Maka dapat diketahui kebutuhan konsumsi penduduk terhadap beras per tahunnya sebagai berikut (sebagai contoh pada Tahun 2013):

\section{KK = Sk x yt}

Dimana:

$\mathrm{KK}=$ kebutuhan konsumsi penduduk (ton /tahun)

$\mathrm{Sk}=$ standar konsumsi $(\mathrm{kg} / \mathrm{kapita} / \mathrm{tahun})$

$\mathrm{yt} \quad=$ Jumlah penduduk tahun $\mathrm{ke}-\mathrm{t}$ (jiwa)

$\mathrm{KK}=99 \mathrm{~kg} / \mathrm{kapita} / \mathrm{tahun} \times 2.230 .717$ (Jumlah penduduk tahun 2013)

$=220.840 .983 \mathrm{~kg} / \mathrm{tahun}$

$=220.840,983$ ton/tahun

Apabila dikonversi ke gabah, dengan angka konversi gabah ke beras sebesar $62,74 \%$, maka kebutuhan gabah pada tahun 2015 adalah sebagai berikut:

$\mathrm{KG}=\mathrm{KKX} 100 / 62,74$

$=220.840,983$ ton/tahun $\mathrm{X} 100 / 62,74$

$=351.994,026$ ton/tahun

Produksi padi pada tahun 2013 berdasarkan data BPS adalah 1.351.668,000 ton. Dengan demikian, pada Tahun 2013 surplus gabah di Kabupaten Karawang adalah 1.351.668 ton - 351.994,026 ton, yaitu sebesar 999.673,974 ton setara dengan 621.548, 851 ton beras. Dengan asumsi produksi beras tetap, sementara jumlah penduduk terus meningkat, maka dapat diperkirakan berkurangnya surplus beras di Kabupaten Karawang sampai dengan Tahun 2033 seperti yang dapat dilihat pada tabel di bawah ini.

Tabel 3: Perkiraan Surplus Gabah Sampai dengan Tahun 2033

\begin{tabular}{|c|c|c|c|c|}
\hline Tahun & $\begin{array}{c}\text { Jumlah } \\
\text { Penduduk } \\
\text { (Jiwa) }\end{array}$ & $\begin{array}{c}\text { Kebutuhan } \\
\text { Gabah } \\
\text { (Ton) }\end{array}$ & $\begin{array}{c}\text { Produksi } \\
\text { (Ton) }\end{array}$ & $\begin{array}{c}\text { Surplus } \\
\text { (Ton) }\end{array}$ \\
\hline 2014 & $2,259,147$ & 356,507 & $1,351,668$ & 995,161 \\
\hline 2015 & $2,287,939$ & 361,051 & $1,351,668$ & 990,617 \\
\hline 2016 & $2,317,098$ & 365,652 & $1,351,668$ & 986,016 \\
\hline 2017 & $2,346,628$ & 370,312 & $1,351,668$ & 981,356 \\
\hline 2018 & $2,376,535$ & 375,031 & $1,351,668$ & 976,637 \\
\hline 2019 & $2,406,823$ & 379,811 & $1,351,668$ & 971,857 \\
\hline 2020 & $2,437,497$ & 384,652 & $1,351,668$ & 967,016 \\
\hline 2021 & $2,468,562$ & 389,554 & $1,351,668$ & 962,114 \\
\hline 2022 & $2,500,023$ & 394,519 & $1,351,668$ & 957,149 \\
\hline 2023 & $2,531,885$ & 399,547 & $1,351,668$ & 952,121 \\
\hline 2024 & $2,564,153$ & 404,639 & $1,351,668$ & 947,029 \\
\hline 2025 & $2,596,832$ & 409,796 & $1,351,668$ & 941,872 \\
\hline 2026 & $2,629,928$ & 415,018 & $1,351,668$ & 936,650 \\
\hline 2027 & $2,663,445$ & 420,308 & $1,351,668$ & 931,360 \\
\hline 2028 & $2,697,390$ & 425,664 & $1,351,668$ & 926,004 \\
\hline 2029 & $2,731,767$ & 431,089 & $1,351,668$ & 920,579 \\
\hline 2030 & $2,766,582$ & 436,583 & $1,351,668$ & 915,085 \\
\hline 2031 & $2,801,841$ & 442,147 & $1,351,668$ & 909,521 \\
\hline 2032 & $2,837,550$ & 447,782 & $1,351,668$ & 903,886 \\
\hline 2033 & $2,873,713$ & 453,489 & $1,351,668$ & 898,179 \\
\hline
\end{tabular}

Sumber: Hasil Perhitungan 
Berdasarkan tabel dan gambar tersebut di atas, dapat dikatakan bahwa nilai surplus gabah di Kabupaten Karawang cenderung menurun dan menjauh dari target 1,5 juta ton gabah. Jumlah penduduk yang tiap tahun meningkat menyebabkan berkurangnya nilai surplus gabah untuk disuplai ke tingkat nasional. Selanjutnya akan dihitung surplus beras dengan beberapa skenario sebagai berikut:

1. Skenario dasar, yaitu intensitas pertanaman dan produktivitas tetap.

2. Skenario peningkatan intensitas pertanaman menjadi 2,5 .

3. Skenario peningkatan produktivitas menjadi 8 ton/ha.

4. Skenario gabungan 2 dan 3

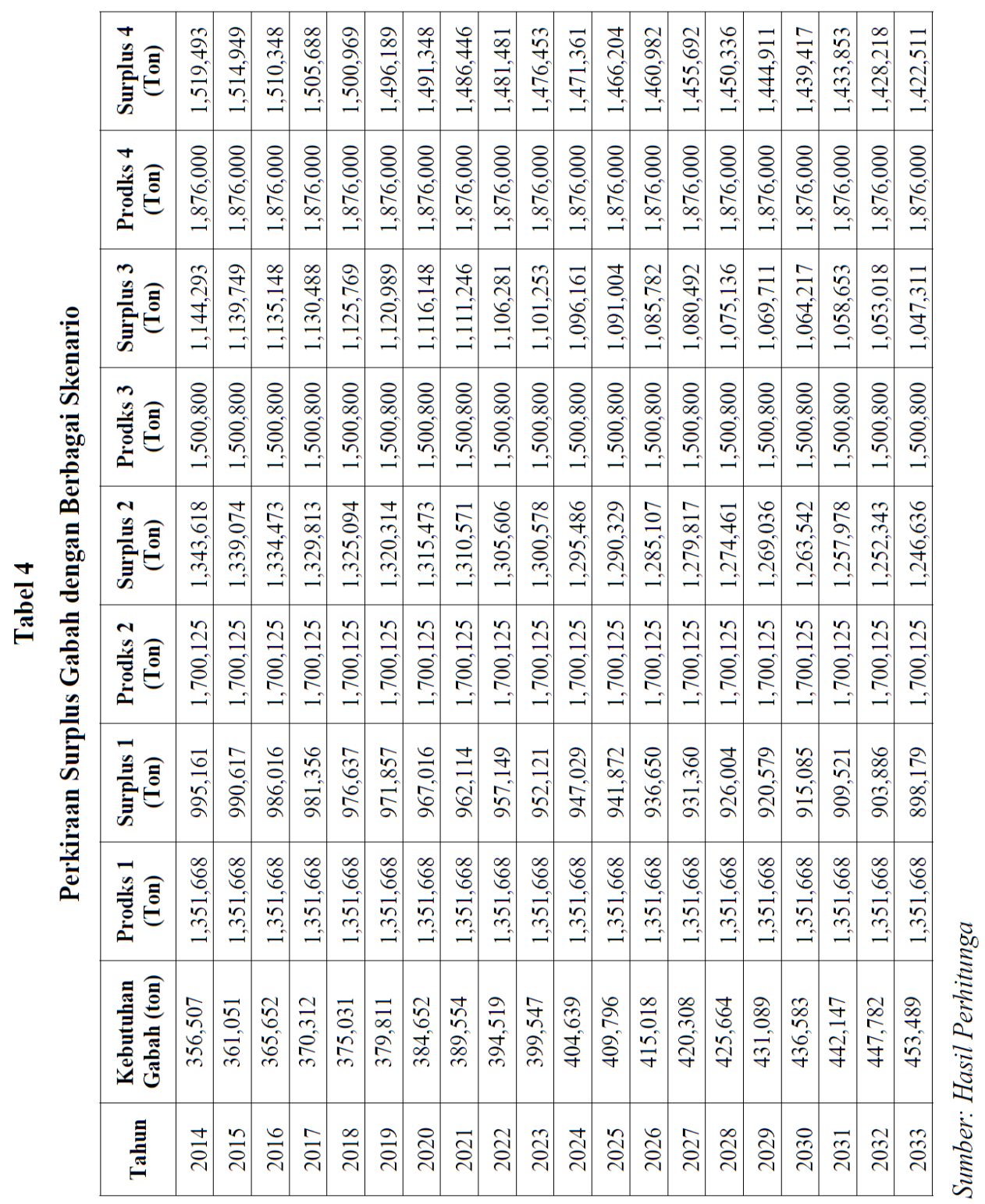

Dari tabel di atas dapat diketahui bahwa surplus gabah sebesar 1,5 juta ton hanya dapat dicapai apabila intensitas pertanaman dan produktivitas ditingkatkan secara bersama-sama. Walaupun demikian, target surplus 1,5 juta ton hanya dicapai selama empat tahun, yaitu sampai Tahun 2017, untuk selanjutnya surplus gabah berkurang lagi hingga kurang dari 1,5 juta ton. Untuk meningkatkan intensitas pertanaman diperlukan jaringan irigasi yang memadai. Intensitas pertanaman sebesar 2,5 artinya bahwa pada 
lahan yang sama ditanam padi lima kali dalam dua tahun, ini artinya perlu didukung dengan keberadaan air irigasi yang harus selalu tersedia.

\subsection{Analisis Kebutuhan Lahan Sawah}

Kebutuhan lahan sawah yang dimaksud di sini adalah apabila Kabupaten Karawang harus surplus gabah sebesar 1,5 juta ton. Luas lahan sawah yang ada sekarang adalah 93.800 hektar, dengan produktivitas 7,25 ton/ha dan intensitas pertanaman 2. Luas lahan sawah sebesar 93.800 hektar dapat memenuhi kebutuhan penduduk Kabupaten Karawang terhadap beras. Akan tetapi apabila harus surplus 1,5 juta ton, maka lahan sawah yang ada sekarang masih harus ditambah. Kebutuhan lahan sawah agar dapat tercapai surplus gabah sebesar 1,5 juta ton dapat dilihat pada Tabel 5, dan kekurangan lahan sawahnya dapat dilihat pada Tabel 6.

Tabe 15: Ke butuhan Lahan Sawah dengan Berbagai Skenario

\begin{tabular}{|c|c|c|c|c|c|c|c|}
\hline Tahun & $\begin{array}{c}\text { Jumlah } \\
\text { Penduduk } \\
\text { (Jiwa) }\end{array}$ & $\begin{array}{c}\text { Keb Gbh } \\
\text { Penduduk } \\
\text { (Ton) }\end{array}$ & $\begin{array}{c}\text { Keb Gbh } \\
\text { Kabupaten } \\
\text { (Ton) }\end{array}$ & $\begin{array}{c}\text { Keb Lhn } \\
\text { Sawah 1 } \\
\text { (Ha) }\end{array}$ & $\begin{array}{c}\text { Keb Lhn } \\
\text { Sawah 2 } \\
\text { (Ha) }\end{array}$ & $\begin{array}{c}\text { Keb Lhn } \\
\text { Sawah 3 } \\
\text { (Ha) }\end{array}$ & $\begin{array}{c}\text { Keb Lhn } \\
\text { Sawah 4 } \\
\text { (Ha) }\end{array}$ \\
\hline 2014 & $2,259,147$ & 356,507 & $1,856,507$ & 128,035 & 102,428 & 116,032 & 92,825 \\
\hline 2015 & $2,287,939$ & 361,051 & $1,861,051$ & 128,348 & 102,679 & 116,316 & 93,053 \\
\hline 2016 & $2,317,098$ & 365,652 & $1,865,652$ & 128,666 & 102,933 & 116,603 & 93,283 \\
\hline 2017 & $2,346,628$ & 370,312 & $1,870,312$ & 128,987 & 103,190 & 116,894 & 93,516 \\
\hline 2018 & $2,376,535$ & 375,031 & $1,875,031$ & 129,313 & 103,450 & 117,189 & 93,752 \\
\hline 2019 & $2,406,823$ & 379,811 & $1,879,811$ & 129,642 & 103,714 & 117,488 & 93,991 \\
\hline 2020 & $2,437,497$ & 384,652 & $1,884,652$ & 129,976 & 103,981 & 117,791 & 94,233 \\
\hline 2021 & $2,468,562$ & 389,554 & $1,889,554$ & 130,314 & 104,251 & 118,097 & 94,478 \\
\hline 2022 & $2,500,023$ & 394,519 & $1,894,519$ & 130,656 & 104,525 & 118,407 & 94,726 \\
\hline 2023 & $2,531,885$ & 399,547 & $1,899,547$ & 131,003 & 104,803 & 118,722 & 94,977 \\
\hline 2024 & $2,564,153$ & 404,639 & $1,904,639$ & 131,354 & 105,084 & 119,040 & 95,232 \\
\hline 2025 & $2,596,832$ & 409,796 & $1,909,796$ & 131,710 & 105,368 & 119,362 & 95,490 \\
\hline 2026 & $2,629,928$ & 415,018 & $1,915,018$ & 132,070 & 105,656 & 119,689 & 95,751 \\
\hline 2027 & $2,663,445$ & 420,308 & $1,920,308$ & 132,435 & 105,948 & 120,019 & 96,015 \\
\hline 2028 & $2,697,390$ & 425,664 & $1,925,664$ & 132,804 & 106,244 & 120,354 & 96,283 \\
\hline 2029 & $2,731,767$ & 431,089 & $1,931,089$ & 133,179 & 106,543 & 120,693 & 96,554 \\
\hline 2030 & $2,766,582$ & 436,583 & $1,936,583$ & 133,557 & 106,846 & 121,036 & 96,829 \\
\hline 2031 & $2,801,841$ & 442,147 & $1,942,147$ & 133,941 & 107,153 & 121,384 & 97,107 \\
\hline 2032 & $2,837,550$ & 447,782 & $1,947,782$ & 134,330 & 107,464 & 121,736 & 97,389 \\
\hline 2033 & $2,873,713$ & 453,489 & $1,953,489$ & 134,723 & 107,779 & 122,093 & 97,674 \\
\hline
\end{tabular}

Sumber: Hasil Perhitungan

Tabel 6: Ke kurangan Lahan Sawah dengan Berbagai Skenario

\begin{tabular}{|l|c|c|c|c|c|c|c|c|}
\hline Tahun & $\begin{array}{c}\text { Keb Lhn } \\
\text { Sawah 1 } \\
(\mathbf{H a})\end{array}$ & $\begin{array}{c}\text { Kek Lhn } \\
\text { Sawah 1 } \\
(\mathbf{H a})\end{array}$ & $\begin{array}{c}\text { Keb Lhn } \\
\text { Sawah 2 } \\
(\mathbf{H a})\end{array}$ & $\begin{array}{c}\text { Kek Lhn } \\
\text { Sawah 2 } \\
(\mathbf{H a})\end{array}$ & $\begin{array}{c}\text { Keb Lhn } \\
\text { Sawah 3 } \\
(\mathbf{H a})\end{array}$ & $\begin{array}{c}\text { Kek Lhn } \\
\text { Sawah 3 } \\
(\mathbf{H a})\end{array}$ & $\begin{array}{c}\text { Keb Lhn } \\
\text { Sawah 4 } \\
(\mathbf{H a})\end{array}$ & $\begin{array}{c}\text { Kek Lhn } \\
\text { Sawah 4 } \\
(\text { Ha) }\end{array}$ \\
\hline 2014 & 128,035 & 34,235 & 102,428 & 8,628 & 116,032 & 22,232 & 92,825 & -975 \\
\hline 2015 & 128,348 & 34,548 & 102,679 & 8,879 & 116,316 & 22,516 & 93,053 & -747 \\
\hline 2016 & 128,666 & 34,866 & 102,933 & 9,133 & 116,603 & 22,803 & 93,283 & -517 \\
\hline 2017 & 128,987 & 35,187 & 103,190 & 9,390 & 116,894 & 23,094 & 93,516 & -284 \\
\hline 2018 & 129,313 & 35,513 & 103,450 & 9,650 & 117,189 & 23,389 & 93,752 & -48 \\
\hline
\end{tabular}




\begin{tabular}{|l|l|l|l|l|l|l|l|r|}
2019 & 129,642 & 35,842 & 103,714 & 9,914 & 117,488 & 23,688 & 93,991 & 191 \\
\hline 2020 & 129,976 & 36,176 & 103,981 & 10,181 & 117,791 & 23,991 & 94,233 & 433 \\
\hline 2021 & 130,314 & 36,514 & 104,251 & 10,451 & 118,097 & 24,297 & 94,478 & 678 \\
\hline 2022 & 130,656 & 36,856 & 104,525 & 10,725 & 118,407 & 24,607 & 94,726 & 926 \\
\hline 2023 & 131,003 & 37,203 & 104,803 & 11,003 & 118,722 & 24,922 & 94,977 & 1,177 \\
\hline 2024 & 131,354 & 37,554 & 105,084 & 11,284 & 119,040 & 25,240 & 95,232 & 1,432 \\
\hline 2025 & 131,710 & 37,910 & 105,368 & 11,568 & 119,362 & 25,562 & 95,490 & 1,690 \\
\hline 2026 & 132,070 & 38,270 & 105,656 & 11,856 & 119,689 & 25,889 & 95,751 & 1,951 \\
\hline 2027 & 132,435 & 38,635 & 105,948 & 12,148 & 120,019 & 26,219 & 96,015 & 2,215 \\
\hline 2028 & 132,804 & 39,004 & 106,244 & 12,444 & 120,354 & 26,554 & 96,283 & 2,483 \\
\hline 2029 & 133,179 & 39,379 & 106,543 & 12,743 & 120,693 & 26,893 & 96,554 & 2,754 \\
\hline 2030 & 133,557 & 39,757 & 106,846 & 13,046 & 121,036 & 27,236 & 96,829 & 3,029 \\
\hline 2031 & 133,941 & 40,141 & 107,153 & 13,353 & 121,384 & 27,584 & 97,107 & 3,307 \\
\hline 2032 & 134,330 & 40,530 & 107,464 & 13,664 & 121,736 & 27,936 & 97,389 & 3,589 \\
\hline 2033 & 134,723 & 40,923 & 107,779 & 13,979 & 122,093 & 28,293 & 97,674 & 3,874 \\
\hline
\end{tabular}

Sumber: Hasil Perhitungan

Berdasarkan kedua tabel tersebut, dan dengan asumsi tidak terjadi alih fungsi lahan sawah di Kabupaten Karawang, maka sampai dengan Tahun 2033, diperlukan tambahan lahan sawah seluas 40.923 hektar apabila tidak ada upaya peningkatan intensitas pertanaman dan produktivitas tanah. Tambahan lahan sawah dapat diperkecil apabila ada upaya peningkatan intensitas pertanaman atau peningkatan produktivitas atau keduanya. Apabila diupayakan peningkatan intensitas pertanaman bersamaan dengan peningkatan produktivitas, maka tambahan lahan sawah yang diperlukan hanya sebesar 3.874 hektar.

Apabila terjadi alih fungsi lahan sawah, maka kebutuhan lahan sawah akan lebih besar lagi. Oleh karena itu lahan sawah yang ada sekarang harus dipertahankan, agar target surplus gabah 1,5 juta ton dapat tercapai. Selain itu, untuk meningkatkan intensitas pertanaman padi dan produktivitas tanah, maka harus didukung oleh jaringan irigasi yang memadai.

\subsection{Analisis Kebutuhan Air Irigasi}

Salah satu upaya meningkatkan produksi padi adalah dengan meningkatkan intensitas pertanaman. Intensitas pertanaman tidak akan bisa maksimal apabila tidak didukung oleh keberadaan air irigasi. Dalam menentukan kebutuhan air digunakan metoda pendekatan agrohidrologi. Kebutuhan air tanaman secara agrohidrologi dapat dilihat pada tabel di bawah ini.

Tabe 1 7: Kebutuhan Air Tanaman Secara Agrohidrologi

\begin{tabular}{|l|c|}
\hline \multicolumn{1}{|c|}{ Kebutuhan Tanaman Padi } & Jumlah (mm/hari) \\
\hline ET & $5-6,5$ \\
\hline Perkolasi & $1-10$ \\
\hline Pengolahan Tanah & $4-30$ \\
\hline Pertumbuhan & $9-20$ \\
\hline Persemaian & $3-5$ \\
\hline Sumber: Partiwijoto (2004)
\end{tabular}

Berdasarkan tabel di atas dapat diketahui kebutuhan air irigasinya yaitu:

$$
\mathrm{KAI}=\mathbf{E T}+\mathbf{P}+\mathbf{K A S}
$$

Dimana : 
KAS = kehilangan air di saluran $(5 \%$ dari $\mathrm{KAL})$

$=0,30 \mathrm{~mm} / \mathrm{hari}$

$\mathrm{KAI}=6,5+10+0,30$

$=16,8 \mathrm{~mm} / \mathrm{hari}$

Kebutuhan air irigasi ini jika dikalikan dengan luas wilayah yang akan dialiri merupakan debit air yang dibutuhkan dari saluran irigasi. Data luas areal yang dipakai adalah luas sawah yang ada di Kabupaten Karawang. Dengan demikian kebutuhan air irigasi untuk sawah seluas 93.800 hektar adalah sebagai berikut:

$$
\begin{aligned}
\mathrm{KAI} & =93.800 \mathrm{Ha} X 16,8 \mathrm{~mm} / \mathrm{hari} \\
& =182,389 \mathrm{~m}^{3} / \mathrm{det}
\end{aligned}
$$

Di Kabupaten Karawang terdapat 7 DAS dengan luasnya masing-masing seperti yang terlihat pada Tabel 8 .

Tabel 8: DAS di Kabupaten Karawang

\begin{tabular}{|c|l|l|r|r|}
\hline No & \multicolumn{1}{|c|}{ Nama DAS } & \multicolumn{1}{|c|}{ Nama Sungai } & \multicolumn{1}{c|}{$\begin{array}{c}\text { Luas } \\
(\mathbf{H a})\end{array}$} & \multicolumn{1}{c|}{$\begin{array}{c}\text { Debit Sungai } \\
\mathbf{m}^{\mathbf{3}} / \mathbf{d e t i k}\end{array}$} \\
\hline 1 & Cibulan-bulan & Cikarokrok & $28.614,9$ & Data tidak tersedia \\
\hline 2 & Ciderewak & Ciderewak & $12.338,2$ & Data tidak tersedia \\
\hline 3 & Cilamaya & Cilamaya & $28.709,4$ & 189,100 \\
\hline 4 & Cisoga & Cisoga & $16.344,8$ & Data tidak tersedia \\
\hline 5 & Ciwadas & Ciwadas & $25.590,2$ & Data tidak tersedia \\
\hline 6 & Sub DAS Cibeet & $\begin{array}{l}\text { Cigentis (Gu-nung Sangga } \\
\text { Buana) }\end{array}$ & $71.989,9$ & $\mathbf{1 3 6 , 5 1 7}$ \\
\hline 7 & Sub DAS Citarum Hilir & Citarum (Tarum Utara) & Jumlah & $\mathbf{3 3 4 , 4 1 7}$ \\
\hline
\end{tabular}

Sumber: Profil CItarum, 2014.

Data debit sungai dari Sungai Cikarokrok, Ciderewak, Cisoga dan Ciwadas tidak tersedia, sehingga dalam penghitungannya keempat sungai tersebut digabungkan dan dilihat dari aliran sungai yang berasal dari Sungai Citarum (Tarum Utara). Keempat sungai tersebut merupakan anak Sungai Citarum (Tarum Utara), seperti yang dapat dilihat pada Gambar 1.

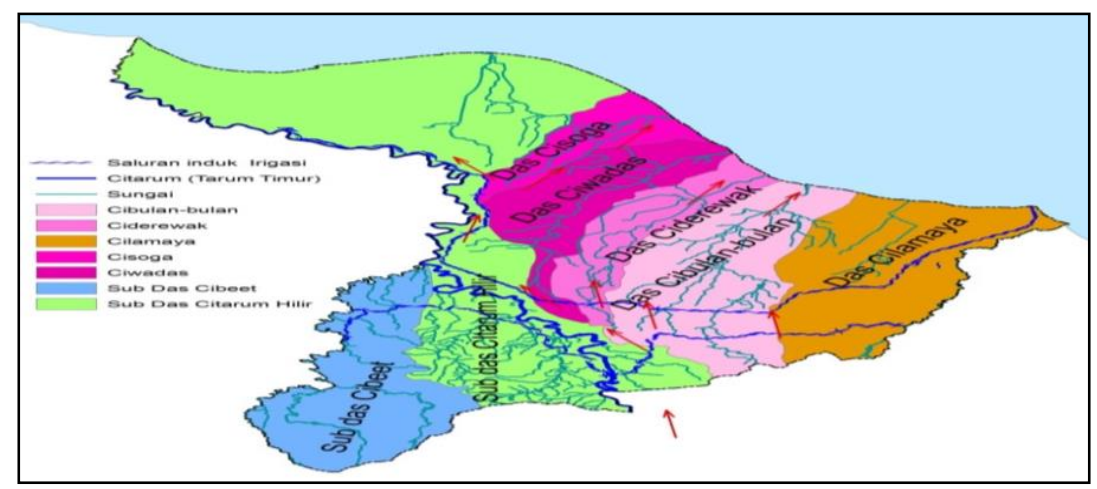

Gambar 1: Pola Aliran Sungai Citarum (Tarum Utara)

Debit air sungai sebesar 334,417 m3/det lebih besar jika dibandingkan dengan kebutuhan air irigasi seluruh sawah yang ada di Kabupaten Karawang, yaitu 182,389 $\mathrm{m}^{3} /$ det, sehingga dapat memenuhi kebutuhan sawah terhadap air irigasi. Keberadaan debit air sungai yang berlebih memungkinkan penambahan luas lahan sawah di Kabupaten Karawang. 


\section{Kesimpulan dan Rekomendasi}

Berdasarkan uraian dalam bab sebelumnya, maka dapat diambil beberapa kesimpulan sebagai berikut:

1. Kabupaten Karawang tidak dapat memenuhi target surplus gabah sebesar 1,5 juta ton apabila penyelenggaraan kegiatan pertanian dilakukan seperti sekarang.

2. Apabila luas sawah tidak berkurang, peningkatan produktivitas tanah dan intensitas pertanaman secara bersamaan dapat menghasilkan surplus gabah sebesar 1,5 juta ton. Walaupun demikian, target surplus 1,5 juta ton ini hanya berlangsung sampai dengan Tahun 2017.

3. Debit air sungai yang melalui Kabupaten Karawang lebih besar jika dibandingkan dengan kebutuhan air irigasi, sehingga dimungkinkan adanya penambahan lahan sawah.

Beberapa rekomendasi yang dapat diajukan sehubungan dengan kesimpulan di atas adalah sebagai berikut:

1. Lahan sawah yang ada di Kabupaten Karawang perlu diproteksi, sehingga pengembangan kawasan permukiman dan industri harus dijauhkan dari lahan sawah

2. Peningkatan produktivitas tanah dan intensitas pertanaman harus didukung oleh jaringan irigasi yang memadai, sehingga jaringan irigasi yang ada harus dipelihara dan ditingkatkan penggunaannya.

3. Dalam jangka panjang, percetakan sawah baru di Kabupaten Karawang harus dilakukan agar target surplu gabah 1,5 juta ton dapat dicapai. Percetakan sawah baru dimungkinkan karena debit air sungai masih cukup memadai.

4. Studi tentang evaluasi lahan untuk percetakan sawah baru perlu dilakukan untuk mengetahui lokasi yang tepat dimana sawah baru harus dialokasikan.

\section{Daftar pustaka}

Anwar, A. 1993. Dampak Alih Fungsi Lahan Sawah Menjadi Lahan Non-Pertanian di Sekitar Wilayah Perkotaan. Jurnal Perencanaan Wilayah dan Kota, Nomor 10, Triwulan IV/ Desember 1993. Bandung.

Arifin, B. 2001. Spectrum Kebijakan Pertanian Indonesia. Penerbit Erlangga. Jakarta.

Arifin, B. 2004. Analisis Ekonomi Pertanian Indonesia. Penerbit Buku Kompas. Jakarta.

Arsyad, S. dan Rustiadi, E. 2012. Penyelamatan Tanah, Air dan Lingkungan. Crestpent Press dan Yayasan Pustaka Obor Indonesia. Jakarta

Badan Pusat Statistik Kabupaten Karawang. 2009 sd 2014. Kabupaten Karawang dalam Angka. 2009 sd 2014..

Barlowe, R. 1978. Land Resorce Economics. Prentice-Hall, Inc., New Jersey.

Eny \& Tugiyono. 1986. Sejarah Terbentuknya Kabupaten Karawang. Penerbit Pustaka Dian. Jakarta.

Irawan, B. 2005. Konversi Lahan Sawah: Potensi Dampak, Pola Pemanfaatannya, dan Faktor Determinan. Forum Penelitian Agro Ekonomi. Volume 23 No. 1, Juli 2005: $1-18$.

Krishnamurti,B. 2004. Arti Penting Pertanian Masa Lalu dan Masa Depan. Jurnal AgroEkonomika N0.2 Tahun XXXIV Oktober 2004, (Diakses Pada Tanggal 27 Juli 2015).

Partowijoto, A. 2004. Kapita Selekta Teknik Tanah dan Air. Jurusan Mekanisasi Pertanian Fakultas Teknologi Pertanian IPB. 
Rustiadi, E., Sunsun., Dyah. 2001. Perencanaan dan Pengembangan Wilayah. Penerbit Crestpent Press dan Yayasan Obor Indonesia. Jakarta.

Sitorus, S.R.P. 1995. Evaluasi Sumberdaya Lahan. Penerbit Tarsito. Bandung.

Suparmoko.M. 2012. Ekonomi Sumber Daya Alam dan Lingkungan, Suatu Pendekatan Teoritis, Edisi 4 Revisi. Penerbit BPFE.Yogyakarta.

Warpani, S. 2001. Analisis Kota dan Daerah. ITB. Bandung.

Winoto, J. 2005. Kebijakan Pengendalian Alih Fungsi Lahan Pertanian. Makalah (Keynote Speech) dipresentasikan dalam Seminar Penanganan Konversi Lahan dan Pencapaian Lahan Pertanian Abadi yang diselenggarakan atas Kerjasama Kantor Kementerian Koordinator Bidang Perekonomian dengan Pusat Studi Pembangunan Pertanian dan Pedesaan (PSP3 - LPPM IPB) di Jakarta, 13 Desember 2005. 